\title{
Experimental and Theoretical Investigations of the Impact Localization of a Passive Smart Composite Plate Fabricated Using Piezoelectric Materials
}

\author{
M. M. S. Dezfouli, ${ }^{1}$ Mohd Roshdi Hassan, ${ }^{2}$ Mohd Hafidz Ruslan, \\ Sohif Mat, ${ }^{1}$ and B. Bakhtyar ${ }^{3}$ \\ ${ }^{1}$ Solar Energy Research Institute (SERI), National University of Malaysia (UKM), 43600 Bangi, Selangor, Malaysia \\ ${ }^{2}$ Department of Mechanical and Manufacturing Engineering, University Putra Malaysia, 43400 Serdang, Selangor, Malaysia \\ ${ }^{3}$ SEFB, COB, University Utara Malaysia (UUM), 6010 Sintok, Kedah, Malaysia
}

Correspondence should be addressed to M. M. S. Dezfouli; salehi.solar@yahoo.com

Received 18 February 2013; Revised 6 May 2013; Accepted 8 May 2013

Academic Editor: Mohd Sapuan Salit

Copyright ( 92013 M. M. S. Dezfouli et al. This is an open access article distributed under the Creative Commons Attribution License, which permits unrestricted use, distribution, and reproduction in any medium, provided the original work is properly cited.

\begin{abstract}
Two passive smart composite plates are fabricated using one and two PZT patches that are cheaper than the PZT wafer. The composite plate is fabricated in low temperature through the hand lay-up method to avoid PZT patch decoupling and wire spoiling. The locus of the impact point is identified using the output voltage to identify the impact location using one sensor. The output voltages of the sensors are analyzed to identify the impact location using two sensors. The locations of the impacts are determined based on the crossing points of two circles and the origin of an intended Cartesian coordinate system that is concentric with one of the sensors. This study proposes the impact location identification of the passive smart composite using the low-cost PZT patch PIC155 instead of common embedded materials (wafer and element piezoelectric).
\end{abstract}

\section{Introduction}

Structural health monitoring systems have recently been developed for various applications. Numerous studies on the different aspects of smart structure systems have been conducted by physicists and engineers in the fields of aerospace, mechanics, and civil engineering [1]. The smart structure system comprises both the host structure, including a laminate composite beam, and the sensing elements (actuations), including piezoceramic patches [2]. The widespread development regarding these systems is caused by the importance and variety of applications of the system in different engineering sciences such as aircraft wing, submarine sterns, and vibration control [3].

One of the most important applications of the systems is the evaluation of the structures of the composite for impact damage and Acoustic Emission (AE), which is applied in damage detection $[4,5]$. Numerous researchers have evaluated acoustic wave propagation and damage detection by embedding or bonding PZT (lead zirconate titanate or piezoelectric ceramic material) sensors/actuators in the composite structure. Studies in the field of damage detection on the use of the PZT sensors/actuators can be divided to active and piezocomposite categories [6].

Active systems use a sensor to detect damage and an actuator. The actuator receives an input voltage and actuates the structure of the composite plate. The resulting acoustic wave is propagated in the composite. The PZT sensor shows an output signal after receiving the $\mathrm{AE}$ wave. If the composite structure has damage, the output signal of the PZT signal is changed. The changes of the signal are evaluated and analyzed by comparing the signal waves before and after the damage $[7,8]$. Passive systems only use the PZT sensor because the $\mathrm{AE}$ created by the impact is propagated through the structure of the composite [9]. The damage detection is analyzed after the PZT sensor receives the AE wave [9]. Guan and Yang monitored the impact damages in the composite laminate to evaluate the output acoustic wave [10]. These researchers 
proved that the $\mathrm{AE}$ wave caused by impact includes important information that describes the composite structure based on the availability or unavailability of the damage. Evaluating the impact behavior of the composite laminate to detect the structural properties of the composite is very complicated; thus, different analysis methods were employed by numerous researchers. Sung et al. analyzed [11] the output signal on the time-frequency domains through the wavelet transform (WT) method and by monitoring the impact on a composite laminate that includes a bonded PZT sensor. In this method, the characteristics of the $\mathrm{AE}$ waves made by impact were analyzed in the passive sending diagnosis (PSD) system on time-frequency domains. Red et al. evaluated the damage detection by the expressing WT as a signal process technique that includes Fourier transforms. Su et al. [12] evaluated the damage identification system, which includes a bonded PZT on a composite bead, based on the acoustic wave propagated by the impact damage.

Diamanti et al. successfully detected the impact damage on a carbon-fiber-reinforced plastic (CFRP) laminate using a PZT patch attached on the composite surface [13]. These researchers detected impact damage by investigating the propagation of the lamb wave and through finite element analysis. Ghoshal et al. evaluated the damage detection based on stress wave parameters by simulating the acoustic wave propagation on a quasi-isotropic glass-epoxy plate that includes a bonded PZT patch based [14]. The previous studies revealed that the PZT patch bonded on the composite plate and embedded piezoelectric materials [15-20], which were used in the previous studies [20-24], could replace other kinds of piezoelectric materials, such as the wafer, that are more expensive than the PZT patch. Therefore, this study fabricates a piezocomposite plate, including four fiberglass layers with one embedded PZT patch through its two intermediate layers through the cut-out method. This paper also investigates the output voltage from the PZT patch through the impact force on the piezocomposites with one PZT patch and two PZT patches.

\section{Material and Methods}

Three methods are available for inserting the PZT patch through composite layers:
(1) smart layer;
(2) inserting without cut-cut;
(3) cut-out method.

Previous studies on embedding piezoelectric materials mainly focused on the application of the PZT wafer using the cut-out method and the application of PZT element using the smart layer method. The current study accordingly employs a PZT patch to embed the materials in the composite layers through the cut-out method by presenting a cost effective design. The cut-out method used in this study to fabricate smart plate and composite materials includes PZT patches, fiberglass rowing, and epoxy.

The piezoelectric materials are the PZT patch PIC155PI Ceramic GmbH (from Germany) is a circular disc with

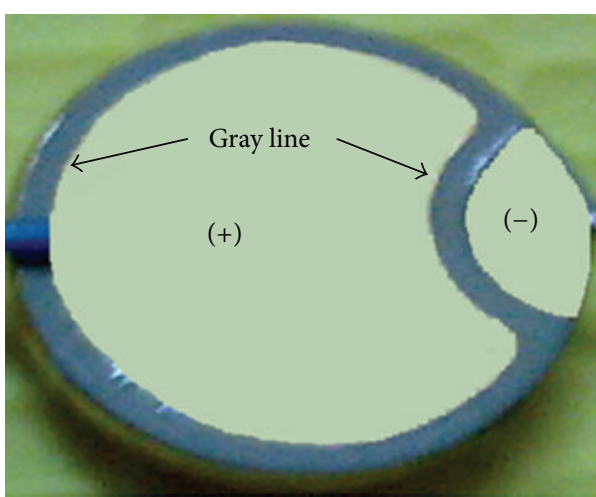

FIGURE 1: PZT patch sensor (PIC155).

TABLE 1: Physical and dielectric properties PIC 155.

\begin{tabular}{lcc}
\hline Parameter & Abbreviation & PIC 155 (PZT) \\
\hline Density & $\rho\left(\mathrm{g} / \mathrm{cm}^{3}\right)$ & 7.80 \\
Curie temperature & $T_{c}\left({ }^{\circ} \mathrm{C}\right)$ & 345 \\
Permittivity & $\varepsilon_{33}{ }^{T}$ & 1450 \\
$\quad \begin{array}{l}\text { In the polarization } \\
\text { direction }\end{array}$ & $\varepsilon_{11}{ }^{T}$ & 1400 \\
$\quad \begin{array}{l}\text { Perpendicular to the } \\
\text { polarity }\end{array}$ & $\tan \delta\left(10^{-3}\right)$ & 20 \\
Dielectric loss factor & & \\
\hline
\end{tabular}

TABLE 2: Mechanical properties of epoxy BBT 7892.

\begin{tabular}{lc}
\hline Mechanical properties & Amount \\
\hline Tensile strength (psi) & 9,800 \\
Tensile modulus (psi) & 420,000 \\
Elongation at break (\%) & 4.9 \\
Flexural strength (psi) & 147,000 \\
Flexural modulus (psi) & 510,000 \\
Compress strength (psi) & 11,900 \\
\hline
\end{tabular}

a $1 \mathrm{~mm}$ thickness and $10 \mathrm{~mm}$ diameter as shown in Figure 1. A gray line shaped like an incomplete circle separates the positive pole $(+)$ of sensor from the negative pole $(-)$.

The interior of the gray circle is the positive pole. The exterior and the sheet behind the sensor are the negative pole. Table 1 shows the physical and dielectric properties of PIC 155.

The fiberglass is an E-glass fiber woven roving (04 XINGDA-DIY Trade-from China) with a $0.25 \mathrm{~mm}$ thickness for each of the layers. The epoxy resin is Epoxy BBT 7892 (Berjaya Bintang Timur Sdn, Bhd Malaysia). Epoxy BBT7892 is a two-component liquid epoxy system specially designed for the wet lay-up laminating process in composite applications. This epoxy resin provides good wetting to most of the composite materials. The details of the properties of BBT-7892 are shown in Table 2.

The process of fabricating the composite plate with the embedded PZT patch has five steps: (i) preparing the mold and epoxy resin, (ii) cut-out fiberglass, (iii) soldering the PZT sensor to the wire, (iv) embedding the PZT sensor into 


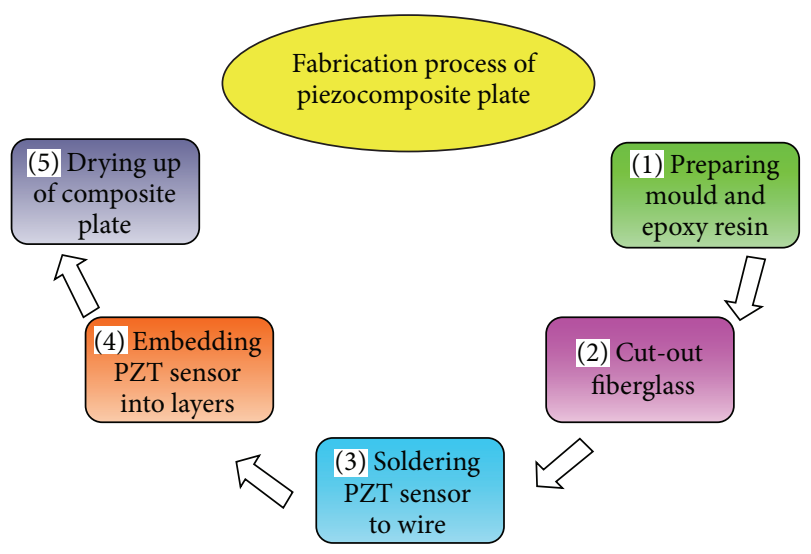

FIGURE 2: Flowchart of fabrication process of piezocomposite plate.

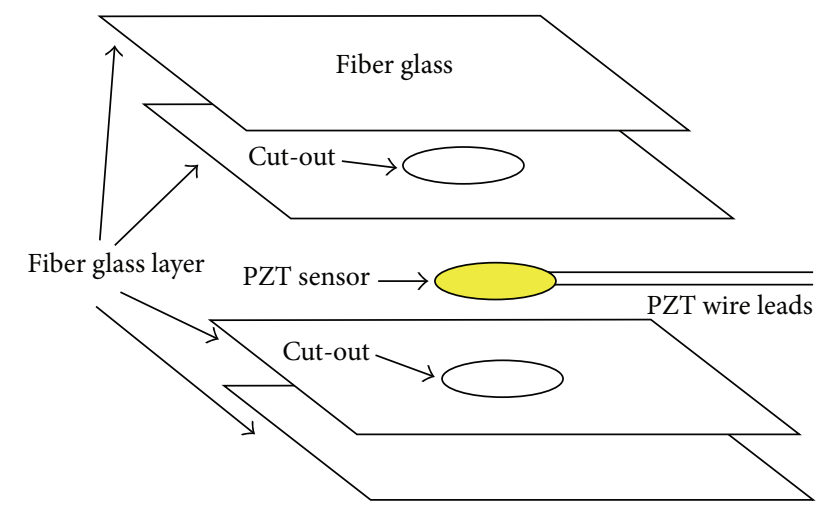

FIGURE 3: Schematic of the embedded piezoelectric into the composite by cut-out method.

layers, and (v) drying up the composite plate. Figure 2 shows the flowchart of the fabrication process of the piezocomposite plate.

Three piezocomposite plates with different specifications were fabricated in this study based on the fabrication process of the composite plate with embedded PZT.

2.1. Fabrication of Piezocomposite Plate with One PZT Patch. The first sample plate included one PZT patch and four layers. The fibers of the first and forth layers had an angle of $45^{\circ}$ with the fibers of second and third layers $\left(45^{\circ} / 90^{\circ} / 90^{\circ} / 45^{\circ}\right)$. In this study, this sample will be called "Sample 1."

One symmetric point in the middle layers of the composite plate was purposely cut-out with the same size as the PZT sensors to embed the sensor in the composite plate (Figure 3).

The plastic sheet holder of the first composite layer was placed on the mold. Next, the second and third layers (cutout layers) were placed on the first layer, where the fibers of second and third layers had an angle of $45^{\circ}$ with the fibers of the first layer (Figure 4).

2.2. Fabrication of Piezocomposite Plate with Two PZT Patches. The second sample plate had two PZT patches and four fiberglass layers. The lay-up of layers was similar to that of Sample 1. In this research, this sample will be called "Sample 2". Two symmetric points with a distance of $12.5 \mathrm{~cm}$ in the middle layers of the composite plate were purposely cut-out in the same size as the PZT sensors to embed the sensors in the composite plate. The PZT patches were then completely inserted through the empty space between the intermediate layers during lay-up processing. Finally, the last layer was placed on the top. After placing each layer, the empty spaces and the bubbles between the layers were reduced using a pressing roller. The last layering step was the placement of the forth layer on the three layers. The fiber on the forth layer had an angle of $45^{\circ}$ with the second and third layers. The lay-up of the composite plate had four layers, and the fibers of the first and the forth layers had an angle of $45^{\circ}$ with the fibers of the second and third layers. Finally, the product was dried in environmental temperature $\left(30^{\circ} \mathrm{C}\right)$ based on the sensitivity of the PZT sensor to the temperature. After dry-up step, a $14 \mathrm{~cm} \times 19.5 \mathrm{~cm}$ composite plate was fabricated; thus, the distance of each sensor to the edge of the composite was $3 \mathrm{~cm}$ and the distance between the two sensors was $12.5 \mathrm{~cm}$.

\section{Experimental Setup}

One of the aims of this study is to investigate the behavior of the output signal because of the impact test on the composite plate with the embedded PZT sensor. The process of the impact test included the production of force using an impact test machine on the composite plate to study the behavior of the composite and the embedded PZT sensor. Figure 5 shows the impact test process, which includes four steps. In the first step, impact was produced using the impact machine on the piezocomposite plate. In the second step, the stress caused by the impact as a mechanical wave was propagated in the plate until reaching the PZT sensor.

In the third step, the crystal structure of the PZT sensor was strained by the effect of the stress because of the impact and made an electrical flow. In the fourth step, the output electrical flow was monitored on the oscilloscope screen in the form of a signal wave (Figure 6).

If an impact happens on point $\mathrm{A}$ of the composite with the PZT Patch, stress is produced. This stress is propagated in form of a mechanical wave through the composite plate and reaches point $B$ near the PZT patch. If the pressure on point $\mathrm{A}$ and $\mathrm{B}$ is equal to $P_{\mathrm{A}}$ and $P_{\mathrm{B}}$, respectively, $P_{\mathrm{B}}$ is less than $P_{\mathrm{A}}\left(P_{\mathrm{B}}<P_{\mathrm{A}}\right)$. This relation is proven through an analysis of the deformation of an element in the one-dimensional stress in Section 3.2.

3.1. Impact Load. Figure 7 shows that the impact on the composite plate is produced by releasing rod from a certain height $(h)$ on the composite plate. The approach velocity of the rod can be obtained using (1)

$$
V^{2}-V_{0}^{2}=2 g\left(h-h_{0}\right),
$$

where $V$ is the velocity of the rod striking the composite plate, $V_{0}$ is the velocity of rod released at zero $(\mathrm{m} / \mathrm{s}), h$ is the height 


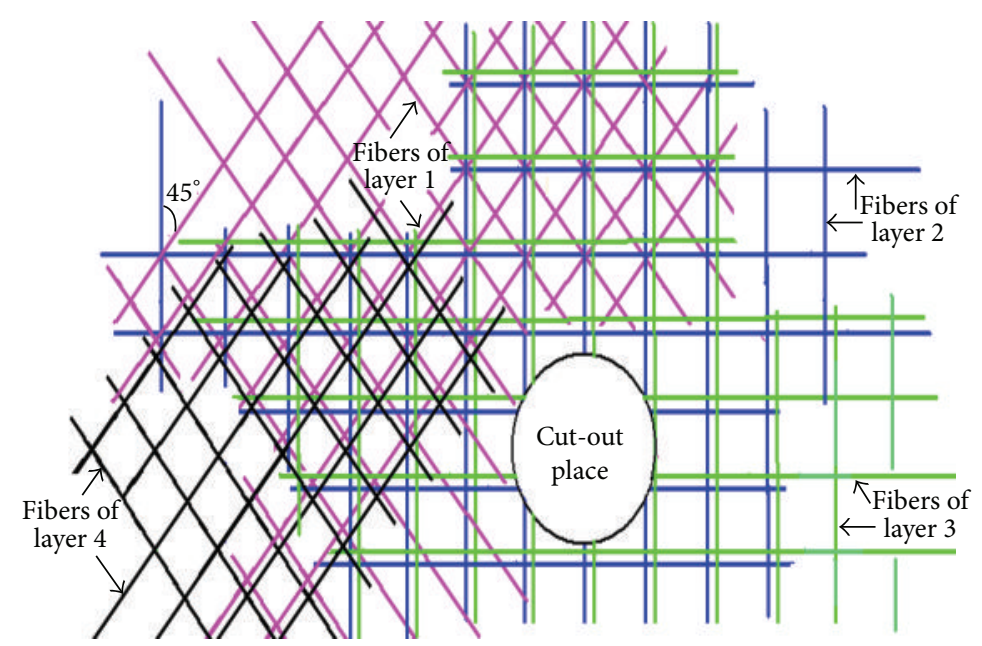

FIgURE 4: Schematic of the Sample 2 structure.

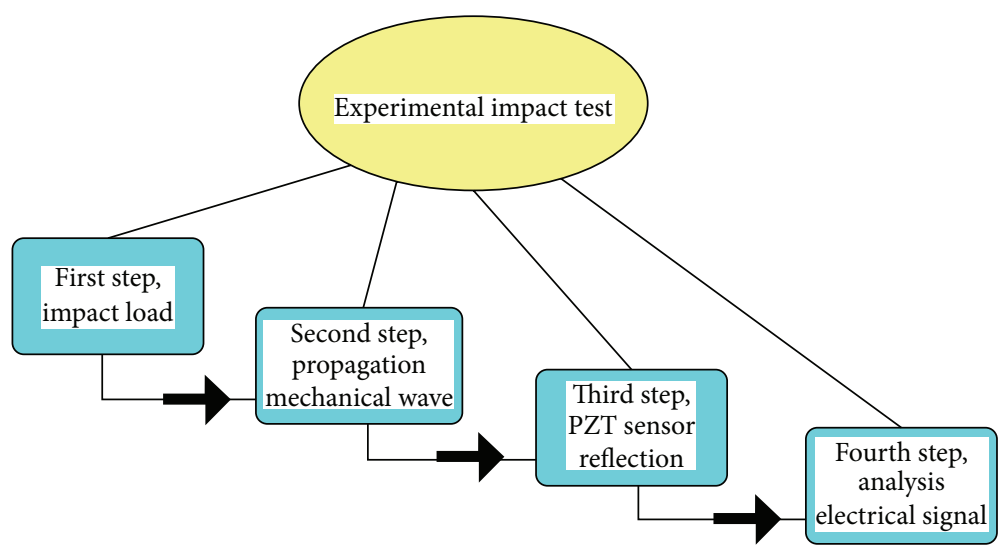

FIGURE 5: Schematic of experimental impact test process.

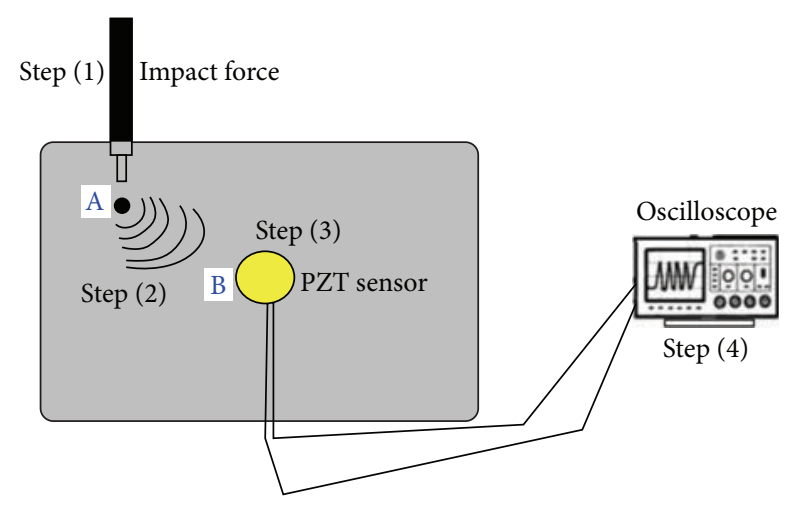

FIGURE 6: Propagation stress wave from impact point (A) to sensor (B).

of rod from the composite plate, and $h_{0}$ is the height of the composite plate considered as zero in this study.

$h_{0}=0$ and $V_{0}=0$ are substituted into (1):

$$
V=\sqrt{2 g h}
$$

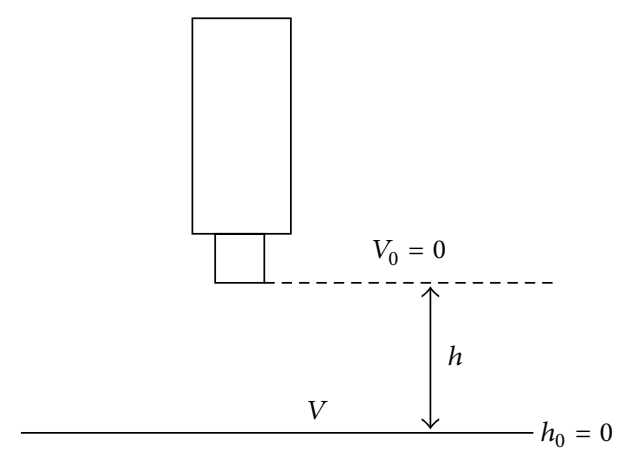

FIGURE 7: Release of the rod on the composite plate.

Newton's law of motion states that $F=m a$ (force equals mass times acceleration) and $a=V / t$ (acceleration equals velocity divided time). Therefore, Newton's laws of motion can be written as

$$
F=m \cdot \frac{V}{t} \quad \text { or } \quad F \cdot t=m \cdot V .
$$


TABLE 3: Force and pressure values at impact point.

\begin{tabular}{lcc}
\hline$h(\mathrm{~m})$ & $F(\mathrm{~N})$ & $P_{0}(\mathrm{~Pa})$ \\
\hline 0.01 & 0.110 & 5642.607 \\
0.02 & 0.157 & 7979.852 \\
0.03 & 0.192 & 9773.282 \\
0.04 & 0.221 & 11285.215 \\
0.05 & 0.248 & 12617.254 \\
0.06 & 0.271 & 13821.509 \\
0.07 & 0.293 & 14928.936 \\
\hline
\end{tabular}

In this study, the time value of the impact test for each point is proposed to be $1 \mathrm{~s}$ (unit of time).

Therefore, the force equation is obtained by (4) by substituting the mass of rod (in this study mass of rod is $m=0.25 \mathrm{~kg})$, time value ( $t=1 \mathrm{~s})$, and (2) into (3),

$$
F=0.25 \sqrt{2 g h}
$$

The pressure at the impact point on the composite plate $\left(P_{0}\right)$ can be calculated using (5):

$$
P_{0}=\frac{F}{A}=\frac{0.25 \sqrt{2 g h}}{\pi r^{2}}=127.3 \sqrt{2 g h},
$$

where $F$ is force $(\mathrm{N}), A$ is the area of the cross-section of the $\operatorname{rod}\left(\mathrm{m}^{2}\right), r$ is the radius of cross-section of the $\operatorname{rod}(\mathrm{m})$, and $P_{0}$ is the pressure at the impact point on the composite plate. In this study, the radius of the cross-section of the rod is $r=$ $0.025 \mathrm{~m}$.

Table 3 shows the force and pressure values at the impact point by changing the releasing height of the rod from the composite plate based on (4) and (5).

3.2. Propagation Mechanical Wave. The waves in the onedimensional longitudinal strain are not the only type of wave motion for a purely longitudinal disturbance. The second type is provided by the wave motion in one-dimensional stress, where the longitudinal normal stresse, for example, $\sigma$, which is only a function of $x$ and $t$, is the one nonvanishing stress component. All other stress components vanish [25].

The deformation of an element in the one-dimensional stress is sketched in Figure 8. The figure shows that the crosssection decreases if the element is in tension. $U(x, t)$ is the longitudinal displacement for the case of one-dimensional stress and is related by [25]

$$
\sigma=E \varepsilon_{x},
$$

where $E$ is Young's modulus. Writing the equation of motion for an element leads to

$$
\frac{\partial \sigma}{\partial x}=\rho \frac{\partial^{2} u}{\partial t^{2}}
$$

The substitution of (6) into (7) yields

$$
\frac{\partial^{2} u}{\partial x^{2}}=\frac{1}{c_{b}^{2}} \frac{\partial^{2} u}{\partial t^{2}}
$$

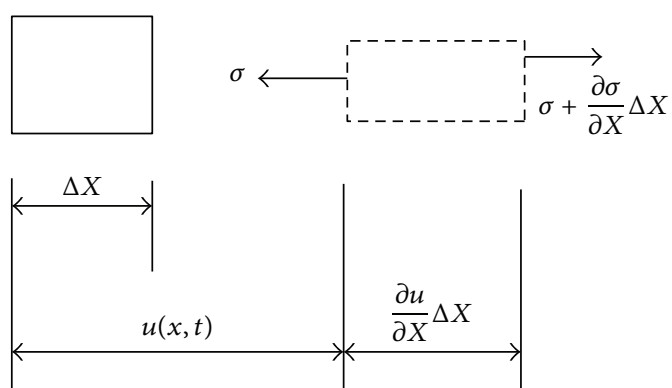

FIGURE 8: Deformation in one-dimensional stress [26].

where

$$
c_{b}^{2}=\frac{E}{\rho} .
$$

The velocity $c_{b}$ is usually called the bar velocity. In this study, Young's modulus of composite plate was achieved through the tensile test, $E=3.2 \mathrm{GPa}$, and the density of composite plate was $\rho=1230 \mathrm{~kg} / \mathrm{m}^{3}$. Therefore, (8) reveals that the velocity of wave propagation in composite plate is $c_{b}=1.62$.

If a semi-infinite thin rod $(x \geq 0)$ is subjected at $x=0$ to a pressure $p(t)$, the resulting stress wave is

$$
\sigma=-P_{0}\left(t-\frac{x}{c_{b}}\right),
$$

where $\sigma$ is the produced stress using $P_{0}$ with a distance of $(x)$ from the impact point, $t$ is the time that the stress reaches the point with a distance of $x$ from an impact point, and $c_{b}$ is the propagation velocity of the wave in the composite plate. Equation (10) was rewritten as

$$
\sigma=-P_{0}\left(\frac{c_{b} t-x}{c_{b}}\right)=-P\left(\frac{\Delta x}{c_{b}}\right) .
$$

The substitution of $x_{\mathrm{A}}$ (impact point) instead of $x$ and $c_{b} t$ instead of $x_{\mathrm{B}}$ yields

$$
P_{\mathrm{B}}=\frac{\sigma \cdot c_{b}}{\Delta x},
$$

where $P_{\mathrm{B}}$ is the pressure at point $\mathrm{B}$, which has a distance of $\Delta x$ from impact point $(\mathrm{A}) ; \sigma$ is the stress because of the pressure $P_{\mathrm{A}}$ in the impact point; and $\Delta x$ is the distance between points $\mathrm{A}$ and $\mathrm{B}$.

The Equation of normal stress is [27]:

$$
\sigma=\frac{F}{A},
$$

where $F$ is impact force $(\mathrm{N})$ and $A$ is area of cross-section of the rod $\left(\mathrm{m}^{2}\right)$. Equation (13) is substituted into (12), which yields (10)

$$
P_{\mathrm{B}}=\frac{F \cdot c_{b}}{\Delta x \cdot A}
$$

In this study $A=19.625 \times 10^{-6} . C_{b}$ is 1.62 . Equation (14) shows that the pressure at point $B$ has an inverse relationship 


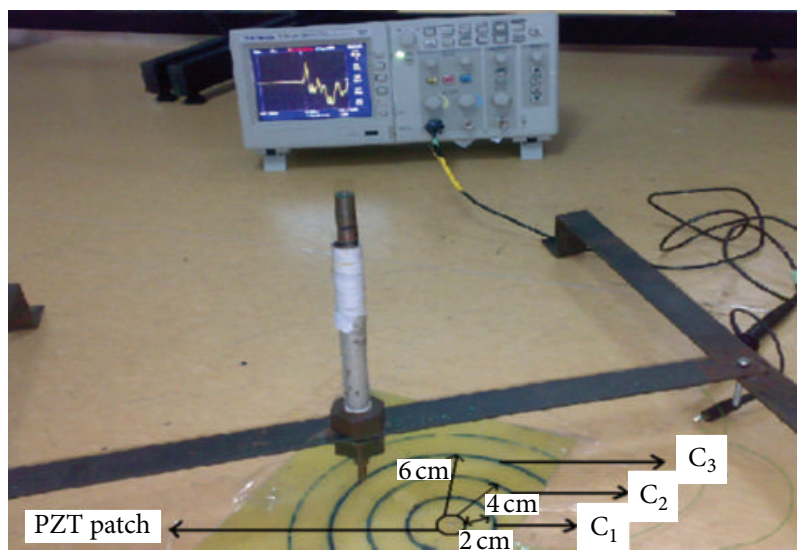

FIGURE 9: Experimental tests with different force values in different points on the composite plate.

with the distance of the impact point from the sensor, which means that the pressure value decreases with the increase of the distance of the impact point $(\Delta x)$. Therefore, $P_{\mathrm{B}}$ is less than $P_{\mathrm{A}}$.

3.3. PZT Reflection. The values of the pressure on the sensors caused by the impacts were calculated by substituting the output voltages in [28]:

$$
P=\frac{16}{3} \frac{\varepsilon_{33}}{d_{31}} \frac{h}{D^{2}} \frac{1}{(1-v)} V
$$

where $\varepsilon_{33}$ is the dielectric constant, $d_{31}$ is the piezoelectric constant, $D$ is the diameter of the PZT sensor, $h$ is the thickness of the PZT sensor, $P$ is the pressure, $V$ is the output voltage, and $v$ is the Poisson ratio. In this study, $\varepsilon_{33}=2.124 \times$ $10^{-9} \mathrm{~F} / \mathrm{m}, d_{31}=-1.65 \times 10^{-10}(\mathrm{~m} / \mathrm{V}), h=0.001(\mathrm{~m}), D=$ $0.01(\mathrm{~m})$, and $v=0.3$.

3.4. Electrical Signals from Oscilloscope. The model of the oscilloscope is TEKTRONIX-TDS2012B with a $100 \mathrm{MHz}$ Bandwidth, $1.0 \mathrm{GS} / \mathrm{s}$ sample rate, and two channels. The data were collected while the oscilloscope voltage selector was set on $10 \mathrm{mV} /$ div. The sensitivity of TEKTRONIX-TDS2012B is $2 \mathrm{mV} / \mathrm{div}$. The impact tests were done on the floor in fixed conditions.

\section{Experimental Procedures}

4.1. Composite Plate with One PZT Patch. Figure 9 shows the experimental procedure on the piezocomposite plate. The impact test on the three circles with radii of 2,4 , and $6 \mathrm{~cm}\left(\mathrm{C}_{1}\right.$ with radii $2 \mathrm{~cm}, C_{2}$ with radii $4 \mathrm{~cm}$, and $C_{3}$ with $6 \mathrm{~cm}$ ), respectively, with their center as the sensor. The relationship between the force and pressure on the sensor was evaluated. Seven forces were placed on the three points with 2,4 , and $6 \mathrm{~cm}$ distance from the sensor by changing the releasing height of the rod from the composite plate $\left(h_{1}=1,2, \ldots, 7 \mathrm{~cm}\right)$.

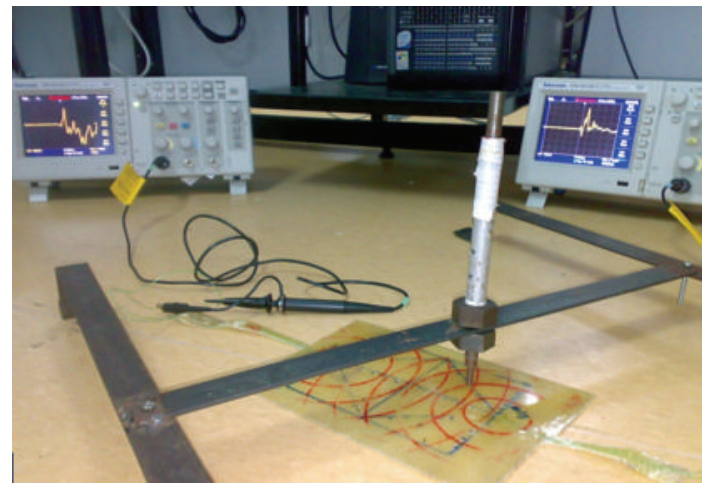

FIgURE 10: Experimental setup on the composite plate with two sensors.

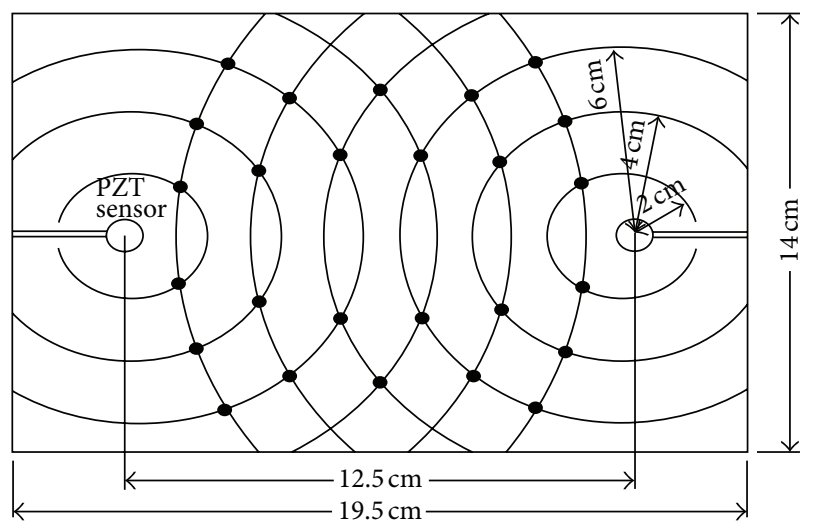

FIGURE 11: Schematic of impact points in the composite plate with two sensors.

Each force on each point caused an output voltage from the sensor. Therefore, seven output voltages existed from each point.

4.2. Composite Plate with Two PZT Patches. Figure 10 shows the experimental setup on the composite plate with two sensors. The principal aim of the current study, which is to localize the impacts, was preceded by drawing the circles with radii of $2,4,6,8,10$, and $12 \mathrm{~cm}$ (the positions of the centers of the sensors) on the composite plate that holds two embedded sensors.

The circles crossed each other in two points (Figure 11). The impact tests were performed on the crossing points. The sensors calibration process was carried out by detecting the impact voltages at the cross points of the circles. The output voltages of the sensors $\left(V_{1}, V_{2}\right)$ were recorded using the oscilloscope to manage the possible error in the experiments for sixfold iterations. The acoustic wave is propagated on the surface of the composite as a result of the application of impact on the smart plate. When the stress wave reached the PZT sensor, the crystal structure of the sensor changed and showed an output signal. The PZT sensor had a symmetrical hexagonal crystal structure that changes with the strain of the stress wave (AE). The output is a free electron in form of a voltage. The oscilloscope displays the measured voltage in the 


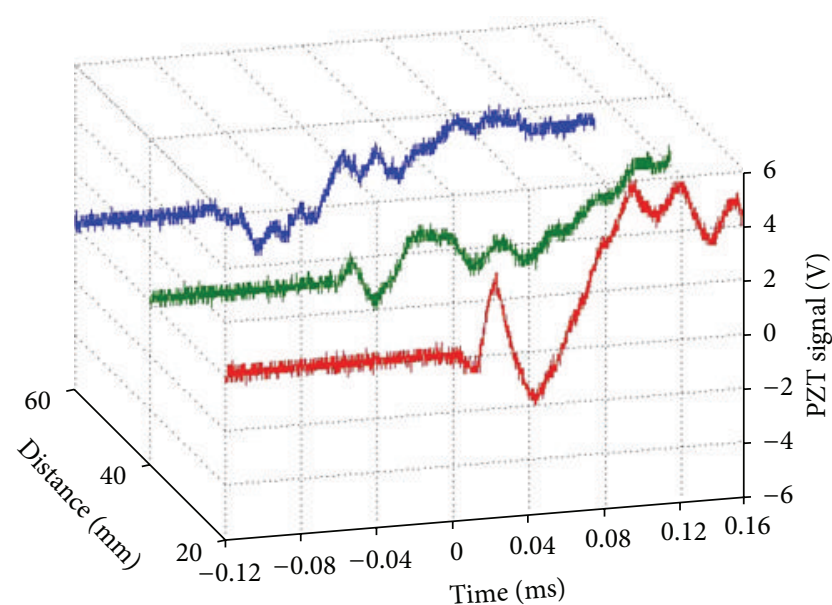

FIGURE 12: First packet of wave output voltage from PZT sensor.

shape of a sinusoidal waveform. The location of the impact load can be determined through the impact monitoring process. The acoustic wave caused by impact should be evaluated and determined in different parts of smart plate to reach the aim of the study.

\section{Results and Discussion}

The results of the impact test on the composite plates with embedded PZT patch are analyzed and evaluated. In the first step, the results of the impact on the two fabricated samples (sample 1 and sample 2) are analyzed. The analysis of the two samples aims to study the manner of the output voltage from the embedded PZT patch by the impact test. In the next step, the result of the impact on the composite plate with two embedded PZT patches (sample 3) is analyzed to find the impact location.

Figure 12 shows that the domain of the first packet of wave decreased by performing the impact test and distancing from the PZT sensor. The first packet of wave with a distance of $20 \mathrm{~mm}$ from the PZT sensor was the maximum. The first packet of the wave with a distance of $60 \mathrm{~mm}$ from the PZT sensor was minimum. Therefore, the domain of the first packet of wave (PK-PK) and the external voltage decreased with the increase of the distance of the impact point from PZT sensor. The cause of this state is demonstrated through the comparison of the theoretical and experimental results.

Figure 13 shows the impact forces versus the pressures on the PZT sensor (experimental results and theoretical results) in which the horizontal axis is the force value for impact and vertical axis is the pressure on the PZT sensor. $\mathrm{C}_{1}, \mathrm{C}_{2}$, and $\mathrm{C}_{3}$ are the names of the three circles with radii of 2 , 4 , and $6 \mathrm{~cm}$ from the PZT sensor. On each line, 7 points (force values) were made to impact on each circle $(2,4$, and $6 \mathrm{~cm}$ from the PZT sensor). The results of the experimental and theoretical impact on the 7 points on each circle (C) are shown as two lines (experimental and theoretical results). Three lines each for the experimental and theoretical results indicate the relationship between the pressure on the sensor

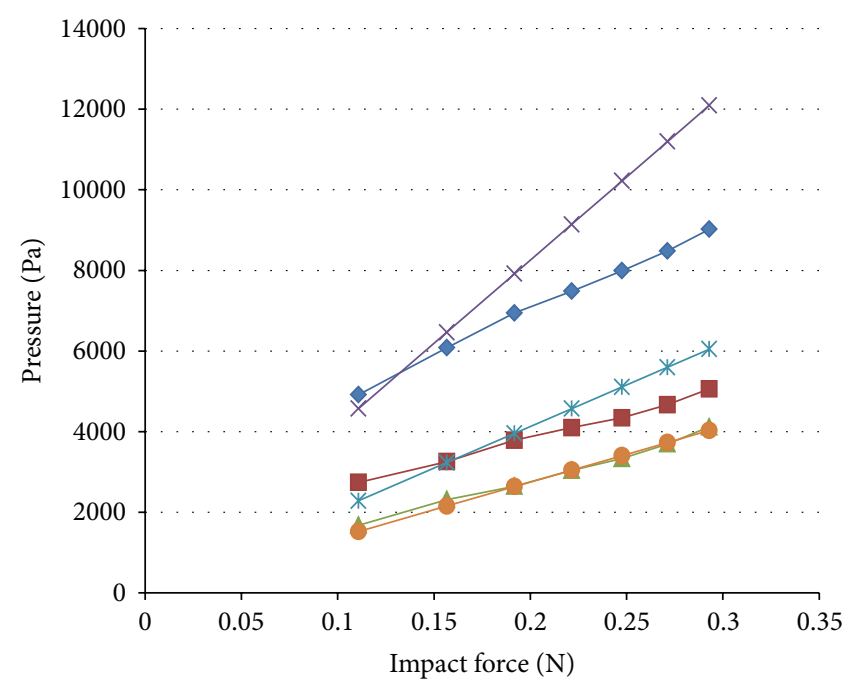

$$
\begin{array}{ll}
\neg \mathrm{C}_{1} \text { experimental }(\text { radii }=2 \mathrm{~cm}) & \leftarrow \mathrm{C}_{1} \text { "theoretical" } \\
-\mathrm{C}_{2} \text { experimental }(\operatorname{radii}=4 \mathrm{~cm}) & -\mathrm{C}_{2} \text { "theoretical" } \\
-\mathrm{C}_{3} \text { experimental }(\operatorname{radii}=6 \mathrm{~cm}) & --\mathrm{C}_{3} \text { "theoretical" }
\end{array}
$$

FIGURE 13: Experimental and theoretical results of the pressure on the sensor versus the impact force values.

and the forces on the points with 2, 4, and $6 \mathrm{~cm}$ distances from the sensor.

The theoretical results were attained through the mentioned equations and the force values in Table 2. These lines have an increasing trend, where the pressure on the sensor increases with the increase of the impact force value on different points of the composite plate.

Therefore, the pressure on the sensor has a direct relationship with the force caused by impact. The difference between lines $C_{1}$ experimental and $C_{2}$ experimental is larger than that between lines $\mathrm{C}_{2}$ experimental and $\mathrm{C}_{3}$ experimental. The impact point recedes the sensor (supposing that force is constant). The pressure on the sensor decreases, and the ratio of the reduction of the pressure decreases. Therefore, the pressure on the sensor has an indirect relationship with the distance of impact point from the sensor. A few points can be gleaned by comparing experimental and theoretical results, which are explained later.

The difference between lines $\mathrm{C}_{1}$ theoretical and $\mathrm{C}_{1}$ experimental increases with the increase of the impact force value. Increasing the impact force value with a distance of $2 \mathrm{~cm}$ from PZT sensor increases the difference of the experimental and theoretical results of pressure on the sensor. Increasing the impact force value also increases the difference between lines $\mathrm{C}_{2}$ theoretical and $\mathrm{C}_{2}$ experimental, which means that the difference of experimental and theoretical results of pressure on the sensor also increases by increasing the impact force value with a distance of $4 \mathrm{~cm}$ from PZT sensor. The lines of $\mathrm{C}_{3}$ theoretical and $\mathrm{C}_{3}$ experimental are almost close to one another, which means that the experimental and theoretical results of pressure on the sensor are almost the same by increasing the impact force value with a distance of $6 \mathrm{~cm}$ from PZT sensor. Therefore, the difference of the experimental and 


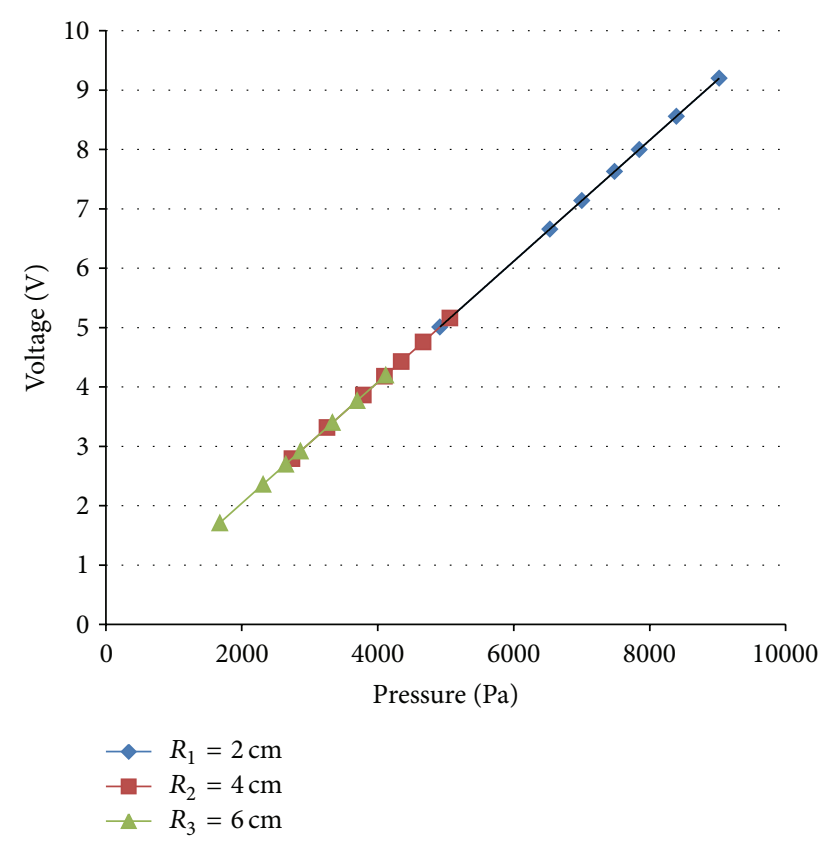

FIGURE 14: Output voltages from the PZT sensor versus pressure on sensor.

theoretical results decreases with the increase of the distance of the impact point from PZT sensor because the sensitivity of the PZT sensor will decrease.

The output voltages from the sensors versus the pressure on the sensor were evaluated using (4) because the pressures on the sensor caused output voltages from the sensor. In Figure 14, the horizontal axis is the pressure on the sensor and the vertical axis is the output voltage. The lines have an increasing trend, which means that the output voltage increases by increasing the pressure on the sensor. The calibration constant is 980.78 , which means that $P=980.78 \times$ $V$.

Therefore, pressure has a direct relationship with voltage. Line $R_{2}$ is below line $R_{1}$, and line $R_{3}$ is below line $R_{2}$, which means that the pressure on the sensor and the output voltage decreases when the impact points recede the sensor. Therefore, the output voltage has an indirect relationship with the distance of the impact point from the sensor.

Figure 15 shows that the locus of the impact point can be identified through the output voltage if the impact occurs on random points of the composite to determine location of impact on the composite plate with a PZT Patch. The locus of the impact was a circle with $R$ as the radius, the sensor as the center. $R$ was obtained from (16):

$$
R=0.104 V+10.01,
$$

where $V$ is the output voltage from the PZT sensor.

5.1. Composite Plate with Two PZT Patches. The impact test on the composite plate with two sensors showed how the output voltage of the two sensors changed because of the change of the distance of the impact point from two sensors. Figure 16 shows the impact points on the composite plate.

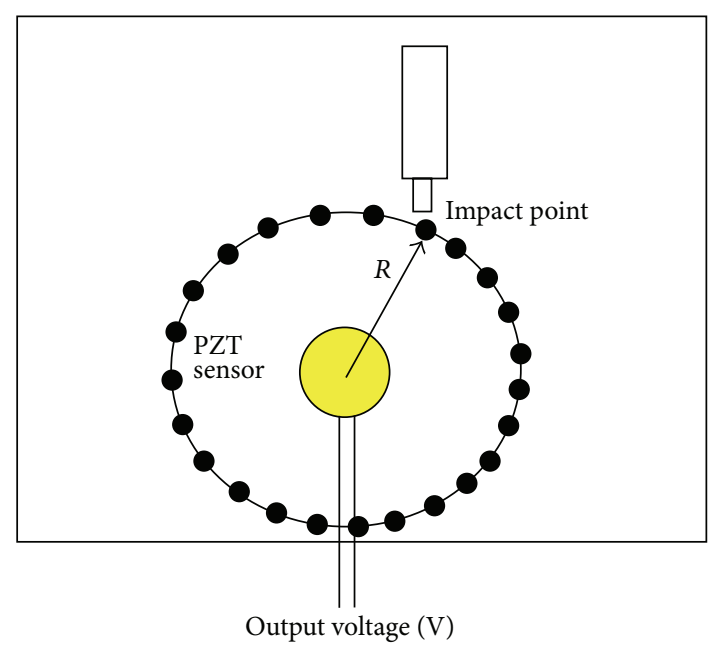

FIGURE 15: Locus of the impact point on the piezocomposite plate with a PZT sensor.

The behaviors of the output voltages of impact points 1 to 6 are similar to those of impact points $1^{\prime}$ to $6^{\prime}$. Therefore, the results of impact points 1 to 6 are similar to the results of impact points $1^{\prime}$ to $6^{\prime}$. Figures $17(\mathrm{a})$ and $17(\mathrm{~b})$ show that the output voltage of sensor one $\left(V_{1}\right)$ is the maximum and the output voltage of sensor two $\left(V_{2}\right)$ is the minimum if the impact point is the crossing point of the two circles with radii of $2 \mathrm{~cm}$ from sensor one and $12 \mathrm{~cm}$ from sensor two. When the impact point distances from sensor one increase and sensor two decrease, $V_{1}$ decreases and $V_{2}$ increases, respectively. In these figures, the horizontal axis is the radius of the circles and the vertical axis is voltage. When the impact point distance to both sensors is equal, $V_{1}$ and $V_{2}$ are almost the same.

$V_{1}$ and $V_{2}$ are the minimum and maximum, respectively, if the impact point is the crossing point of the two circles with radii of $2 \mathrm{~cm}$ from sensor one and $12 \mathrm{~cm}$ from sensor two. The analysis of the results of the impact test on the crossing points of the circles showed that the output voltage of PZT sensor had an adverse relationship with the distance of the impact point from the sensors. An impact test using two sensors was conducted across the different points of the composite plate with the aim of impact localization through test data analysis. The impact test data include the output voltages of the two sensors in terms of the distances of the impact points from the sensors. In a composite plate with two sensors, the distances of the impact point to sensors $1\left(R_{1}\right)$ and $2\left(R_{2}\right)$ and the value of the output voltage from the sensors $1\left(V_{1}\right)$ and 2 $\left(V_{2}\right)$ are shown in Figure 18. An impact on a point on the page between the two sensors occurred. Two values of voltage from the two sensors were obtained. The results from the impact on different parts of composite plate showed that the voltage values from each sensor could determine the impact point distance to each sensor.

The Output voltage of the first sensor $\left(V_{1}\right)$ indicates the location of the impact point in terms of the radial distance $\left(R_{1}\right)$ from the first sensor. The output voltage of $\left(V_{2}\right)$ indicates the location of the impact point in terms of the radial distance $\left(R_{2}\right)$ from the second sensor. The impact locations 


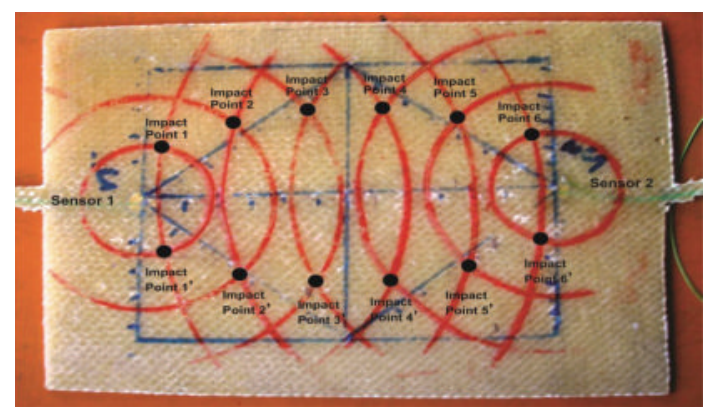

FIGURE 16: Impact points on the composite plate with two PZT sensors.

are obtained as two symmetric points generated because of the intersection of the circles. Therefore, the coordinates of the impact locus point had to be calculated to obtain the position of the impact locus point using two sensors. The origin of the coordinates was intended on the sensor 1; thus, the $X$-axis was matched on the center line of the two sensors and the $Y$-axis was perpendicular to the sensor. The distance between sensors 1 and 2 was $12.5 \mathrm{~cm}$. The impact locus points were assumed to be $A(x,-y)$ and $A(x, y)$ to determine these two points.

The equation of the intersection of the two circles intersection was written as (17), where $(x, y)$ is the coordinate of point $\mathrm{A}, R_{1}$ is the radius to the center of sensor 1 , and $R_{2}$ is the radius to the center of sensor 2 ,

$$
\begin{gathered}
x^{2}+y^{2}=R_{1}^{2}, \\
(x-12.5)^{2}+y^{2}=R_{2}^{2} .
\end{gathered}
$$

Equation (17) is written as

$$
\begin{gathered}
y^{2}=R_{1}^{2}-x^{2}, \\
x^{2}+y^{2}-25 x+156.25=R_{2}^{2} .
\end{gathered}
$$

The calculation of (18) results to (19) and (20):

$$
\begin{gathered}
x=\frac{R_{2}^{2}-R_{1}^{2}-156.25}{25}, \\
y= \pm \sqrt{R_{1}^{2}-x^{2}} .
\end{gathered}
$$

Therefore, (19) and (20) show that the values of radius $R_{1}$ and $R_{2}$ had to be determined to determine the values of $x$ and $y$. The values of the output voltage from the two sensors $\left(V_{1}\right.$ and $V_{2}$ ) were examined and analyzed through two methods.

Method 1. The distance values of the impact point from each sensor were considered using the voltage from the same sensor to determine $R_{1}$ and $R_{2}$. For instance, the relation between $R_{1}$ and $V_{1}$ was obtained by analyzing the distance values of the impact point to sensor 1 through the voltage resulting from sensor $1\left(V_{1}\right)$,

$$
R_{1}=-3.807 \operatorname{Ln}\left(V_{1}\right)+7.3467 \text {. }
$$

Equation (21) shows that the distance of the impact point to sensor 1 was obtained by acquiring the output voltage from sensor 1 . The relation of $R_{2}$ with $V_{2}$ was also determined by analyzing the distance values of the impact point to sensor 2 through the voltage from sensor 2 ,

$$
R_{2}=-2.647 \operatorname{Ln}\left(V_{2}\right)+5.9979 .
$$

Equation (22) shows that the distance of impact point to sensor 2 was obtained by acquiring the output voltage from sensor 2. Therefore, the distance value of the impact point can be determined from each sensor using the output voltage from each sensor through (21) and (22). $R_{1}$ and $R_{2}$ according to (21) and (22) are determined from (21) and (22) by obtaining $V_{1}$ and $V_{2}$ from the impact. The coordinates $(x, y)$ of the impact point are determined by inserting the value of $R_{1}$ and $R_{2}$ in (19) and (20).

Method 2. The relationship between the distance of the impact point from each sensor with two variables of $V_{1}$ and $V_{2}$ was determined to obtain an impact location with a higher accuracy than the method 1. For example, the distance values of the impact point to sensor $1\left(R_{1}\right)$ obtained by achieving the values from the two sensors $\left(V_{1}, V_{2}\right)$ were analyzed. Figure 19 shows that the vertical axis is the distance of the impact point to sensor $1\left(R_{1}\right)$, the horizontal axis is the output voltage from sensor $1\left(V_{1}\right)$, and the perpendicular axis to the page is the output voltage from sensor $2\left(V_{2}\right)$. Therefore, the inverse relationship of the voltage change with a change in the distance of the impact point from the sensor in this page holds true. For instance, a decrease in the distance of the impact point from sensor $1\left(R_{1}\right)$ from point $\mathrm{A}$ to point $\mathrm{B}$ caused by the short distance of the impact point to sensor 1 leads to an increase in the output voltage from sensor $1\left(V_{1}\right)$. The output voltage from sensor 2 also decreases because the impact point is farther from sensor $2\left(R_{2}\right)$. Therefore, the relation of $R_{1}$ with the two variables of $V_{1}$ and $V_{1}$ was analyzed through MATLAB and was written as

$$
R_{1}=7.404-0.88 V_{1}+0.83 V_{2} .
$$

Therefore, (23) shows that $R_{1}$ can be calculated if $V_{1}$ and $V_{2}$ are obtained from the impact on each point of composite page. Equation (23) detected the distance of the impact point from sensor $1\left(R_{1}\right)$; thus, $V_{1}$ and $V_{2}$ were the output voltages from sensors 1 and 2, respectively. In the next step, the distance values of the impact point to sensor $2\left(R_{2}\right)$, acquired by obtaining the values from the two sensors $\left(V_{1}, V_{2}\right)$, were analyzed. Figure 20 shows that the vertical axis is the distance of the impact point from sensor $2\left(R_{2}\right)$, the horizontal axis is the output voltage from sensor $2\left(V_{2}\right)$, and the perpendicular axis on a page is output voltage from sensor $2\left(V_{1}\right)$.

The page was drawn using three variables $\left(R_{2}, V_{1}\right.$, and $\left.V_{2}\right)$; thus, the indirect relation of the voltage change with distance change of the impact point from the sensor holds true. For example, the voltage of sensor 2 decreases if the distance of the impact point to sensor 2 from point $A$ to point $B$ increases in this page because the impact point moves farther from sensor 2 . The voltage of sensor $1\left(V_{1}\right)$ also increases because the impact point moves nearer to sensor 1 . Therefore, 


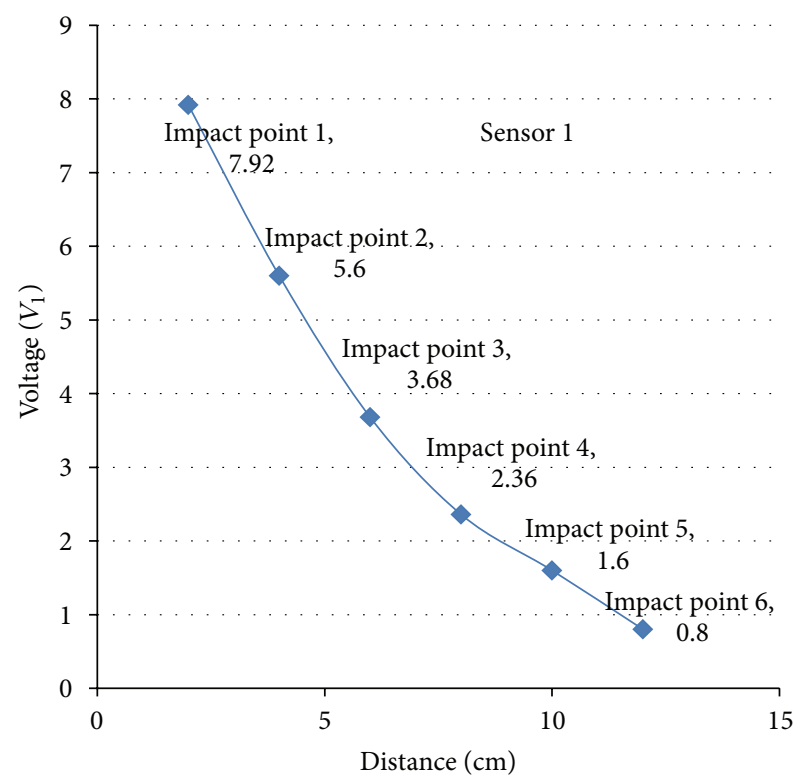

(a)

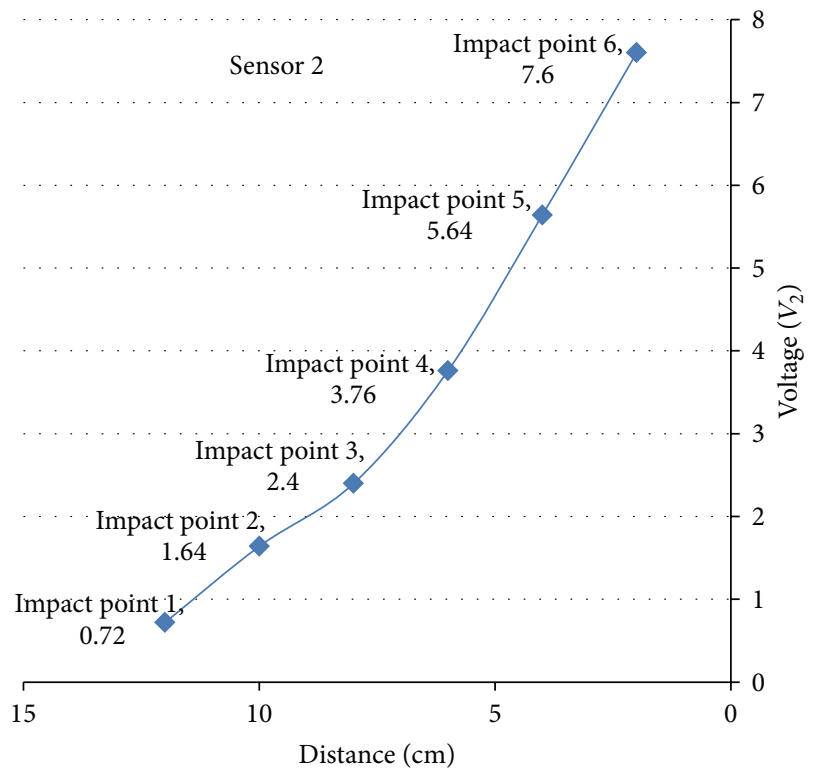

(b)

FIGURE 17: Behavior of output voltage from the two sensors.

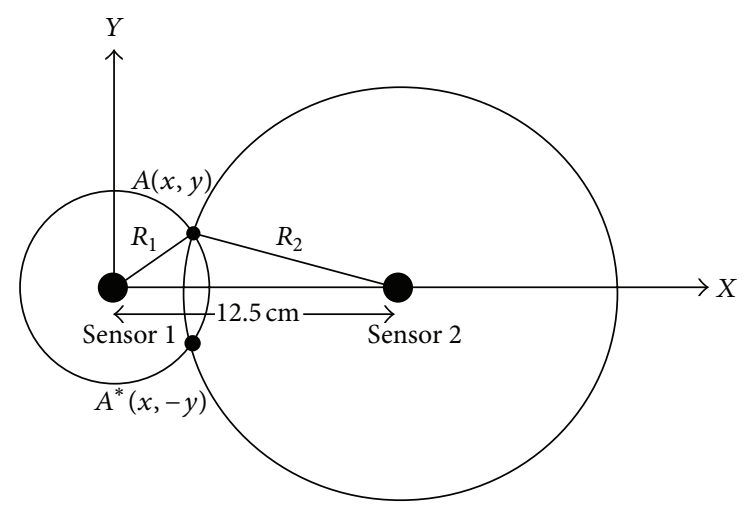

FIGURE 18: Intersection of two circles to detect impact location.

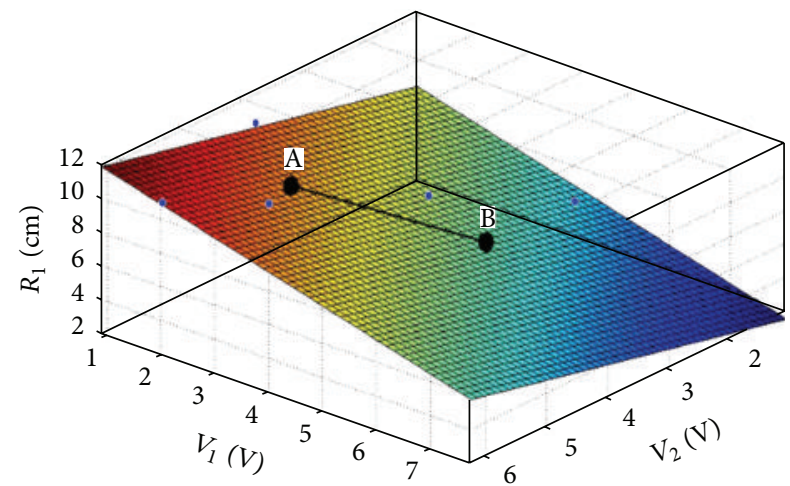

FIGURE 19: Distance of the impact point from sensor $1\left(R_{1}\right)$ versus the two output voltages from the two sensors $\left(V_{1}\right.$ and $\left.V_{2}\right)$.

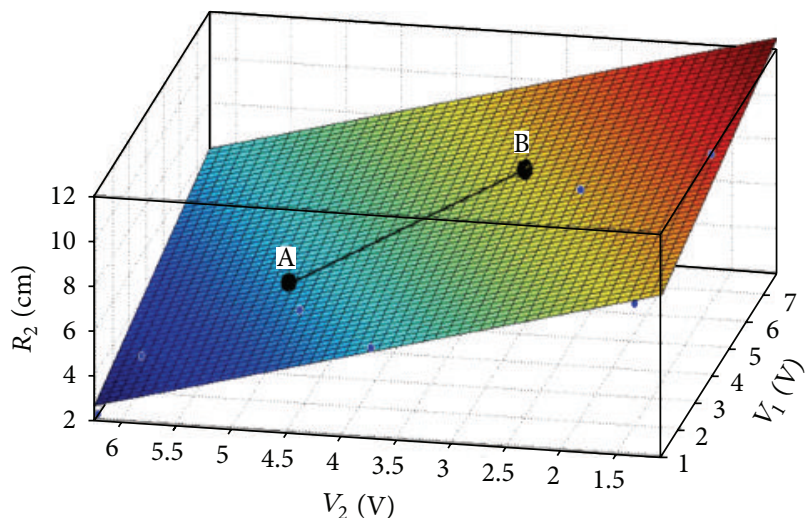

FIGURE 20: Distance of the impact point from sensor $2\left(R_{2}\right)$ versus the two output voltages from the two sensors $\left(V_{1}\right.$ and $\left.V_{2}\right)$.

the relationship of $R_{2}$ with the two variables of $V_{1}$ and $V_{2}$ was analyzed through MATLAB, which achieved (17):

$$
R_{2}=10.2+0.476 V_{1}-1.286 V_{2} .
$$

Therefore, the distance of the impact point from each sensor $\left(R_{1}, R_{2}\right)$ is obtained by achieving the output voltage from the two sensors $\left(V_{1}, V_{2}\right)$ and inserted (17) or (24) if an impact is inserted between the two sensors on a composite plate. The coordinates $(x, y)$ or $(x,-y)$ of the impact point can also be achieved by inserting the values of $R_{1}$ and $R_{2}$ in (19) and (20).

Embedding PZT into the composite technique as a passive smart structure is suitable in damage detection. Passive approaches do not affect any actuators, and receivers are used to "sense and/or hear" any perturbations caused by possible 
hidden damage [6]. Numerous researchers have studied the passive smart structure using the bonded PZT patch on the composite for damage detection [1-5]. Embedding PZT in composite has some advantages, such as the protection of PZT from environmental effects, prevention of wire spoiling, and the increase of the PZT lifetime, compared with the bonding method. The result in this study shows that embedding the PZT patch method for passive smart structures is applicable to damage detection in a composite plate.

\section{Conclusions}

This paper presents experimental and theoretical investigations on impact localization on two piezocomposite plates, including one and two embedded PZT patches, through the cut-out method.

The signal from the embedded PZT patch was detected through the impact on the fabricated composite plate with an embedded one PZT patch. The value of external voltage was found to decrease by increasing the distance of the impact point from the PZT sensor. Therefore, the locus of the impact point can be identified using the output voltage if an impact occurs on the random points of the composite. The locus of the impact was a circle with $R$ as the radius and the sensor as the center.

The current study attempts to determine the location of the impact points through the cut-out method and the two embedded PZT patches inside the four-layered composite plate. The fabricating process was conducted at a low temperature using the hand lay-up method to avoid wire spoiling and the decoupling of the PZT patch. The utilized fabrication process is a highly cost-effective manufacturing prototype model considering the cost advantages of using the PZT patch compared with the PZT wafer. The location of the impact points was determined by analyzing the output voltages of the PZT sensors, which were embedded among the composite layers. The applied impact to the page between the sensors resulted in the generation of voltage through the sensors. The output voltage of the sensors determined the distance of each of the imposed impacts from the sensors. The output voltage of the first sensor $\left(V_{1}\right)$ indicated the location of the impact based on the radial distance $\left(R_{1}\right)$ from the first sensor. The output voltage of $\left(V_{2}\right)$ indicated the location of the impact point based on the radial distance $\left(R_{2}\right)$ from the second sensor. The location of the impacts is obtained as two symmetric points and is generated as an intersection of the two circles. Therefore, determining the coordinates of the impact locations is necessary to obtain the locations of impacts. The coordinates of the two symmetrical impact points are defined with the origin of the intended coordinate system as the location of sensor 1 .

\section{Abbreviations}

PZT: Lead zirconate titanate $(\mathrm{Pb}[\mathrm{Zr}(\mathrm{x}) \mathrm{Ti}(1-\mathrm{x})] \mathrm{O} 3)$

AE: Acoustic emission

WT: Wavelet transform
PSD: Passive sending diagnosis

CFRP: Carbon-fiber-reinforce plastic

$P: \quad$ Pressure $(\mathrm{Pa})$

F: $\quad$ Force $(\mathrm{N})$.

\section{Acknowledgment}

The authors would like to thank the Mechanical Department of University Putra Malaysia for providing the laboratory facilities and technical support.

\section{References}

[1] J. Wang, "Modeling dynamic of composite plate with PZT patches embedded by using FEMLAB3," in Proceedings of the COMSOL Multiphysics User's Conference 2005 Stockholm, 2005.

[2] A. Zabihollah, R. Sedagahti, and R. Ganesan, "Active vibration suppression of smart laminated beams using layerwise theory and an optimal control strategy," Smart Materials and Structures, vol. 16, no. 6, pp. 2190-2201, 2007.

[3] S. M. Yang, "Design and fabrication of a smart layer module in composite laminated structures," Smart Materials and Structures, vol. 14, no. 2, pp. 315-320, 2005.

[4] S. G. Pierce, B. Culshaw, G. Manson, K. Worden, and W. J. Staszewski, "Application of ultrasonic Lamb wave techniques to the evaluation of advanced composite structures," in Proceedings of the 7th Annual International Symposium on Smart Structures and Materials. International Society for Optics and Photonics (SPIE's '00), 2000.

[5] M. M. S. Dezfouli, Z. Hashim, M. H. Ruslan et al., "Experimental investigation of solar hybrid desiccant cooling system in hot and humid weather of malaysia," in Proceedings of the 10th International Conference on Environment, Ecosystems and Development (WSEAS '12), 2012.

[6] M. Yocum, H. Abramovich, A. Grunwald, and S. Mall, "Fully reversed electromechanical fatigue behavior of composite laminate with embedded piezoelectric actuator/sensor," Smart Materials and Structures, vol. 12, no. 4, pp. 556-564, 2003.

[7] F. Mustapha, G. Manson, K. Worden, and S. G. Pierce, "Damage location in an isotropic plate using a vector of novelty indices," Mechanical Systems and Signal Processing, vol. 21, no. 4, pp. 1885-1906, 2007.

[8] M. M. S. Dezfouli, Z. Azran, M. H. Ruslan, K. Sopian, and B. Bakhtyar, "Experimental investigate of draying chilli by solar assisted heat pump dryer with multifunctional solar thermal collector," in International Conference on Environment, Ecosystems and Development, 2012.

[9] W. J. Staszewski, S. Mahzan, and R. Traynor, "Health monitoring of aerospace composite structures-active and passive approach," Composites Science and Technology, vol. 69, no. 11-12, pp. 1678-1685, 2009.

[10] Z. Guan and C. Yang, "Low-velocity impact and damage process of composite laminates," Journal of Composite Materials, vol. 36, no. 7, pp. 851-871, 2002.

[11] D. Sung, C. Kim, and C. Hong, "Monitoring of impact damages in composite laminates using wavelet transform," Composites Part B, vol. 33, no. 1, pp. 35-43, 2002.

[12] Z. Su, L. Ye, X. Bu, X. Wang, and Y. W. Mai, "Quantitative assessment of damage in a structural beam based on wave propagation by impact excitation," Journal of Civil Structural 
Health Monitoring, vol. 2, no. 1, Article ID 145792, pp. 27-40, 2003.

[13] K. Diamanti, J. M. Hodgkinson, and C. Soutis, "Detection of low-velocity impact damage in composite plates using lamb waves," Structural Health Monitoring, vol. 3, no. 1, pp. 33-41, 2004.

[14] A. Ghoshal, W. N. Martin, M. J. Schulz, A. Chattopadhyay, W. H. Prosser, and H. S. Kim, "Health monitoring of composite plates using acoustic wave propagation, continuous sensors and wavelet analysis," Journal of Reinforced Plastics and Composites, vol. 26, no. 1, pp. 95-112, 2007.

[15] I. Kim, H. Lee, and J. Kim, "Impact damage detection in composite laminates using PVDF and PZT sensor signals," Journal of Intelligent Material Systems and Structures, vol. 16, no. 11-12, pp. 1007-1013, 2005.

[16] J. Han, C. Kim, and J. Kim, "The propagation of Lamb waves in a laminated composite plate with a variable stepped thickness," Composite Structures, vol. 76, no. 4, pp. 388-396, 2006.

[17] D. Lee, Fundamentals of Shock Wave Propagation in Solids, Springer, Berlin, Germany, 2008.

[18] C. Yoon, S. Lee, S. Lee, H. Kim, and K. Lee, “Transverse 13 piezoelectric ceramic/polymer composite with multi-layered PZT ceramic blocks," Sensors and Actuators, vol. 134, no. 2, pp. 480-485, 2007.

[19] J. Park, J. Kong, D. Kim, and D. Yoon, "Nondestructive damage detection and interfacial evaluation of single-fibre/epoxy composites using PZT, PVDF and P(VDF-TrFE) Copolymer sensors," Composites Science and Technology, vol. 65, no. 2, pp. 241-256, 2005.

[20] J. Barton, "Smart structures and materials Brian Culshaw," in Optics and Lasers in Engineering, vol. 27, pp. 337-338, Artech House, Boston, MA, USA, 1997.

[21] M. Arous, H. Hammami, M. Lagache, and A. Kallel, "Interfacial polarization in piezoelectric fibre-polymer composites," Journal of Non-Crystalline Solids, vol. 353, no. 47-51, pp. 4428-4431, 2007.

[22] D. Sung, C. Kim, and C. Hong, "Monitoring of impact damages in composite laminates using wavelet transform," Composites Part B, vol. 33, no. 1, pp. 35-43, 2002.

[23] S. W. Doebling, C. Farrar, and P. Cawley, "Damage identification and health monitoring of structural and mechanical systems from changes in their vibration characteristics: a literature review," Los Alamos National Laboratory Report LA-13070-M, 1996.

[24] Z. Su, L. Ye, X. Bu, X. Wang, and Y. Mai, "Quantitative assessment of damage in a structural beam based on wave propagation by impact excitation," Structural Health Monitoring, vol. 2, no. 1, pp. 27-40, 2003.

[25] J. D. Achenbach, Wave Propagation in Elastic Solids, vol. 16, North-Holland, Amsterdam, The Netherlands, 1973.

[26] F.-H. Chou and J. D. Achenbach, "Three-dimensional Vibrations of Orthotropic cylinders," Journal of the Engineering Mechanics Divisione, vol. 98, pp. 813-822, 1972.

[27] S. J. Kirk and A. J. Dell'Isola, Life Cycle Costing For Design Professionals, McGraw-Hill, New York, NY, USA, 1995.

[28] J. G. Webster, The Measurement, Instrumentation, and Sensors Handbook, Springer, 1999. 

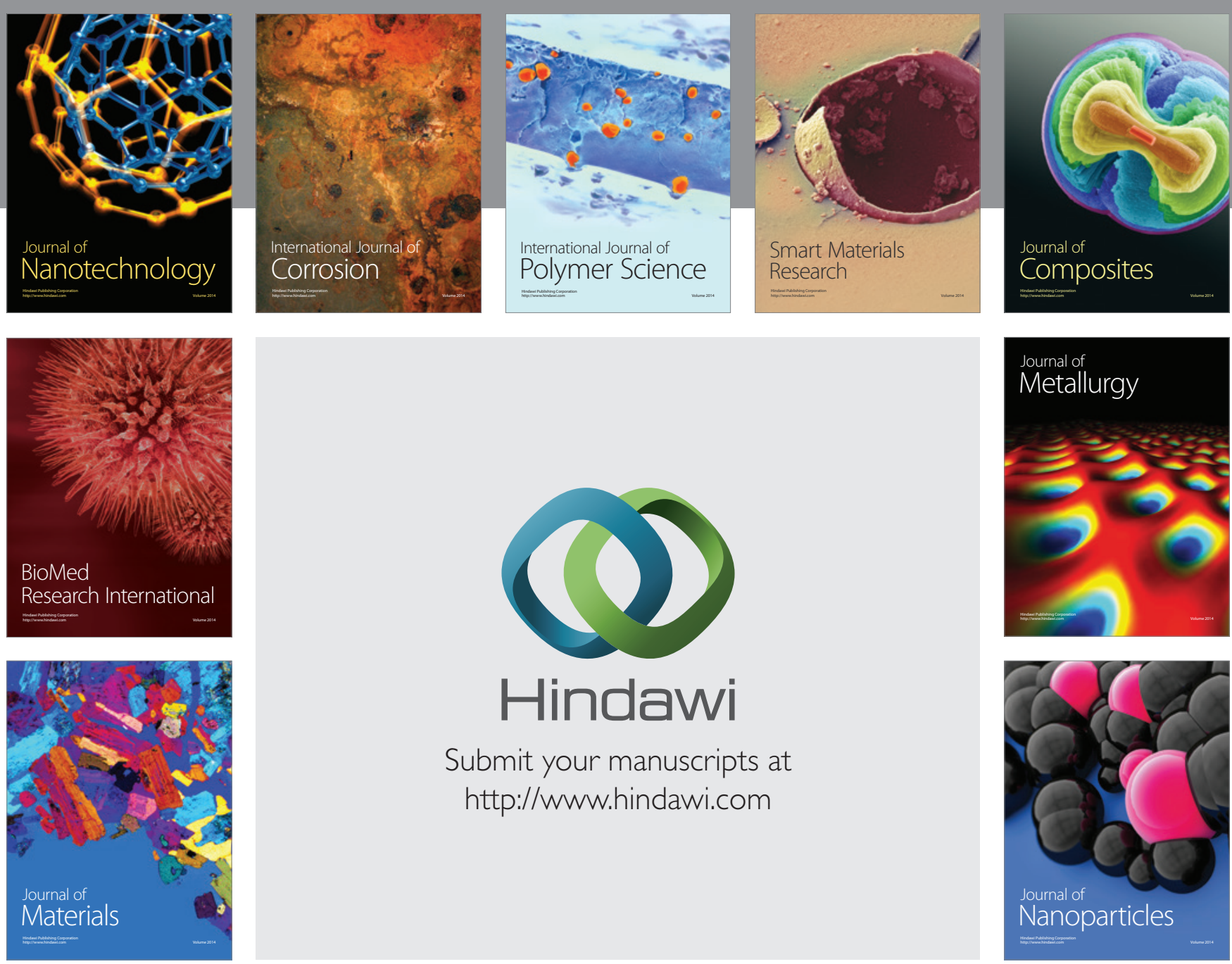

Submit your manuscripts at http://www.hindawi.com
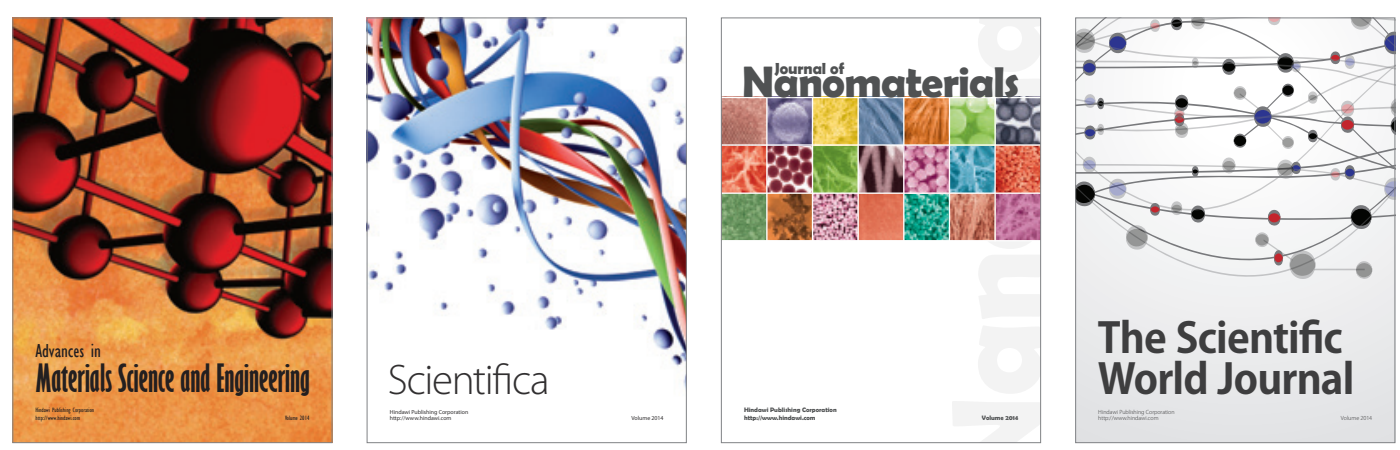

\section{The Scientific World Journal}
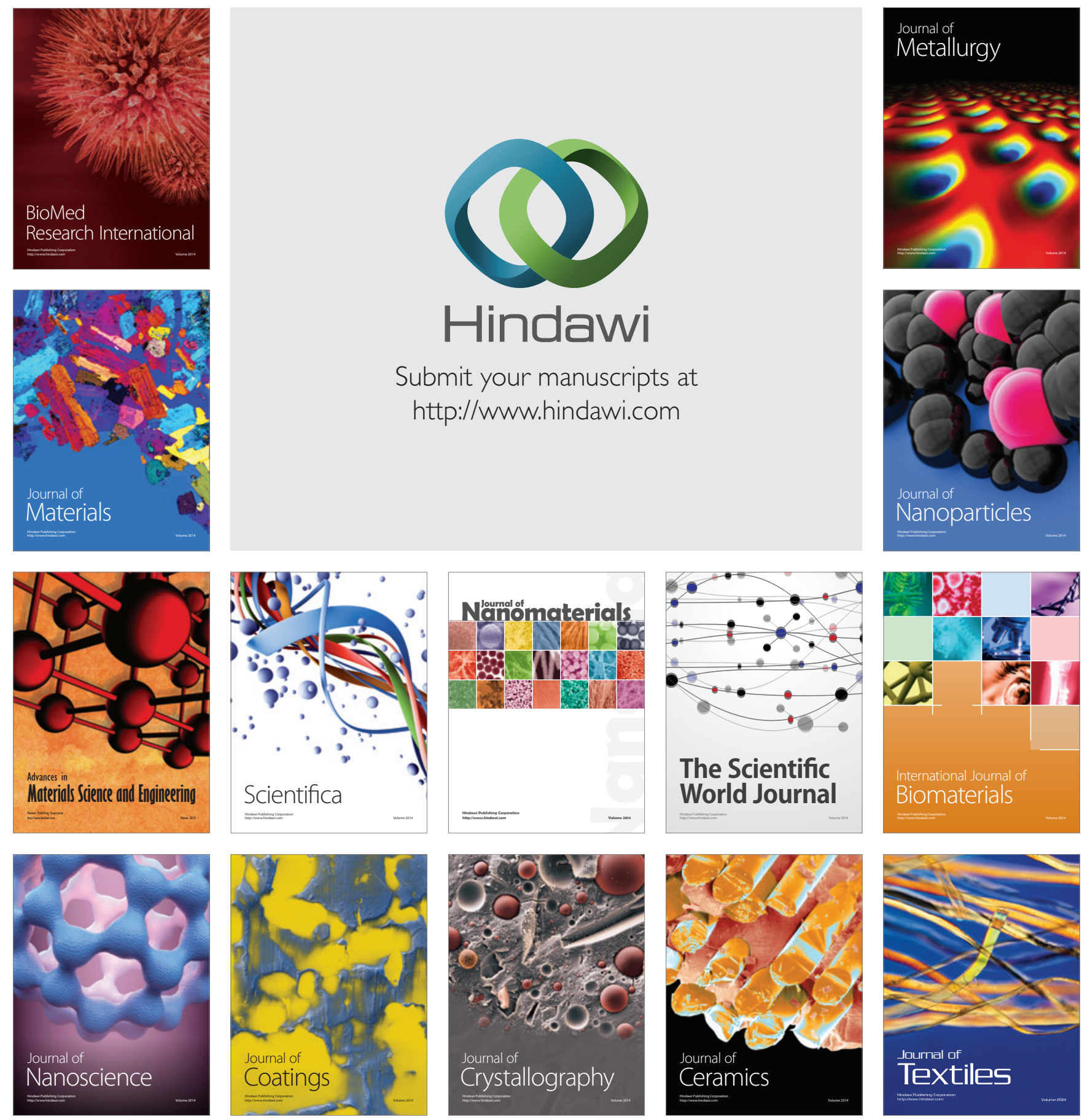